\title{
Dermatological aspects influencing the practice of physical activities by obese individuals
}

\author{
Aspectos dermatológicos que influenciam a \\ prática de atividades físicas em obesos
}

Kátia Sheylla Malta Purim, Ana Cláudia Kapp Titski, Neiva Leite*

Universidade Federal do Paraná (UFPR), Curitiba, PR, Brazil

\begin{abstract}
Objective: The aim of this study was to perform a systematic review of the major skin diseases affecting obese individuals and their influence on physical activity. Methods: Relevant articles were identified by systematically searching PubMed from 2000 to 2014, using the descriptors "skin diseases" and "obesity", "skin disease" and "obesity", "skin diseases" and "physical activity", "skin disease" and "physical activity". The PEDro Scale (in Brazilian Portuguese) was used to rate the methodological quality of the studies. Results: A total of 320 articles were examined in the first phase. In the end, 11 articles met the proposed criteria and were included for analysis in the systematic review. We investigated cutaneous manifestations of diseases and classified them according to their effects under 5 categories: metabolic $(n=10)$, aesthetic $(n=$ $7)$, inflammatory $(n=6)$, mechanical $(n=5)$ and infectious $(n=3)$. The most frequent dermatoses among obese were acanthosis nigricans, acrochordon (skin tags), stretch marks, plantar keratodermia, intertrigo, bacterial and fungal infections. Acanthosis nigricans was found to be the most important metabolic implication of obesity. Conclusion: Although neglected, skin lesions are common in obesity and have implications
\end{abstract}

* KSMP: PhD, e-mail: kspurim@gmail.com ACKT: MSc, e-mail: anaclaudiakt@gmail.com NL: PhD, e-mail: neivaleite@gmail.com 
for physical activity because they cause pain, discomfort, friction, infection, inflammation, embarrassment, limitation or difficulty of movement. Strategies to promote skin health may result in a better integration of physical activity into routine therapy and improve the quality of life of obese individuals.

Keywords: Obesity. Skin diseases. Quality of life. Physical activity. Health.

\section{Resumo}

Objetivo: $O$ objetivo deste trabalho foi realizar revisão sistemática das principais dermatoses no obeso e sua influência na prática de atividades físicas. Método: Os artigos relevantes foram identificados por busca sistemática no Pubmed, publicados de 2000 a 2014, com os descritores "skin diseases" e "obesity", "skin disease" e "obesity", "skin diseases" e "physical activity", "skin disease" e "physical activity Para a pontuação da qualidade metodológica dos artigos foi utilizada a Escala de PEDro - Português (Brasil). Resultados: A fase inicial totalizou 320 artigos. Ao final, após a verificação dos critérios propostos, foram mantidos 11 artigos para análise na revisão sistemática, que investigaram manifestações cutâneas classificadas em repercussões metabólicas ( $n=10)$, estéticas $(n=7)$, inflamatórias $(n=6)$, mecânicas $(n=5)$ e infecciosas $(n=3)$. As dermatoses mais frequentes foram acantose nigricans, acrocordons, estrias, ceratodermia plantar, intertrigo, infecções bacterianas e fúngicas, sendo as repercussões metabólicas, em especial, a acantose nigricansa principal representante. Conclusão: Embora negligenciadas, as lesões dermatológicas são comuns na obesidade e apresentam implicações nas atividades físicas pela dor, desconforto, atrito, infecção, inflamação, constrangimento, limitação ou dificuldade na execução dos movimentos. Ações de promoção da saúde cutânea podem resultar em melhor integração da atividade física na rotina terapêutica e na qualidade de vida do obeso.

Palavras-chave: Obesidade. Dermatoses. Qualidade de vida. Atividade física. Saúde.

\section{Introduction}

Obesity causes organic manifestations with varying impacts and repercussions (1-7). The main effects of obesity on skin physiology are related to the barrier function, the sebaceous and sweat glands, the hairs, the structure and function of collagen, the cicatrization of wounds, the subcutaneous fat, the lymphatic drainage and the microcirculation $(2,4,8$ 16) Dermatoses are more evident in severe obese individuals due to the large portions of skin that are exposed to friction, distension and the formation of folds. In addition, these individuals are more likely to develop diabetes, hypertension, metabolic, cardiovascular and orthopedic disorders, as well as associated comorbidities $(5,7,17)$.

Skin lesions generate significant costs to all involved and influence patient's quality of life, as well as their social, recreational and work relationships $(7,18)$ Dermatoses may serve as metabolic markers of obesity and insulin resistance (19-24). Depending on their appearance, location and circumstances, they can cause embarrassment and hinder or prevent the practice of physical and sporting activities (3, 4, 25-28).

Studies have shown that skin disorders in obese individuals can vary in severity, prevalence and response to treatment. They are caused by changes in the skin surface pattern (keratosis pilaris, stretch marks, xanthomas, acrochordons, gynecomastia) (2, 29-31); hyperandrogenism and hyperinsulinemia (acanthosis nigricans, acne, hirsutism, androgenetic alopecia) (20,32-35); increased prevalence of infection (candidiasis, dermatophytosis, folliculitis, furuncles, erythrasma, erysipelas, cellulitis, necrotizing fasciitis) (14, 36-38); decreased venous return (chronic venous insufficiency, lymphedema, stasis dermatitis and delayed healing of wounds) $(13,36)$. They are also associated with the occurrence of ingrown toenails, keratodermas and calluses on the feet $(14,25)$; and worsening in the severity of psoriasis (39-42), seborrhea (43-44) and diabetes symptoms $(4,23,35,45)$. Skin lesions may affect the self-esteem of patients, cause discomfort, pain, ergonomic overload and mechanical limitations in performing certain body movements. 
Considering that the early identification of dermatoses can play an important role in primary prevention through the encouragement of lifestyle change, reception of specific treatment and improvements in self-image $(18,46-49)$, this study discusses the skin changes that are related to obesity, emphasizing their influence on physical activity and aiming at health promotion and disease prevention.

\section{Methods}

We systematically searched PubMed (National Library of Medicine) from January 2000 to March 2014. The following descriptors were used in combination: "Skin diseases" and "obesity"; "Skin disease" and "obesity"; "Skin diseases" and "physical activity", "skin disease" and "physical activity". A total of 320 articles were examined in the first phase. The combination of the three keywords ("skin diseases", "obesity" and "physical activity") resulted in 246 studies. However, these studies were not included in the analysis because they did not meet the eligibility criteria. The lists of references of systematic reviews were manually searched to identify studies that might have been overlooked in the initial search. Primary and secondary articles were included in the analysis, and special attention was given to original studies related to the central research question.

During the selection process, the papers found were examined, screened, and analyzed for examination if they met the eligibility and inclusion criteria of this study . After removal of duplicate articles, all potentially eligible articles were screened by reading their titles and abstracts to check whether the studies met the inclusion and exclusion criteria. Only original articles published in Portuguese, English or Spanish from 2000 to 2014 and associating obesity and physical activity with dermatoses were included in this systematic review. Systematic review articles, meta-analyses, editorials, abstracts published in congresses, animal studies and articles on skin diseases related to cancer were excluded.

The PEDro Scale (in Brazilian Portuguese) was used to rate the methodological quality of the studies (50), according to seven aspects: 1) Control group; 2) Group Similarity; 3) Sample calculation performed; 4) Use of reliable assessment instruments; 5) Appropriate statistical analysis; 6) QUALIS B1 or higher; and 7) Sample composed by more than 30 subjects.
This selection process was performed by two independent reviewers and studies were included only after consensus review and agreement by all reviewers. In cases of disagreement, a third reviewer was consulted.

Obesity has been defined as the excessive accumulation of fat in the adipose tissue, in body parts or in the whole body, and a body mass index exceeding $30 \mathrm{~kg} / \mathrm{m}^{2}(3,4)$. Physical activity has been defined as any movement that results in more energy expenditure than rest and is the result of voluntary muscle contraction (51).

For the purposes of this study, dermatoses have been defined as common skin changes that affect obese individuals and result in complaints, discomfort or greater demand for medical care. The etiological and pathological classification of skin disorders associated with obesity was adapted from the ABESO (Brazilian Association for the Study of Obesity and Metabolic Syndrome) (4). Dermatoses were divided according to their effects into 5 categories: 1) metabolic; 2) mechanical; 3) infectious; 4) inflammatory; 5) aesthetic. After this classification, skin problems were analyzed within each group of dermatoses according to their possible impact on physical activity.

\section{Results}

Of 320 articles identified, 11 met the proposed criteria and were included for analysis in the systematic review. (Figure 1).

Tables 2 and 3 separately show the summaries of the studies that related obesity to skin diseases and physical activity, according to their rating on the PEDro scale.

\section{Discussion}

The growing modernization of societies, the increase in sedentary lifestyle and dietary changes have led obesity to reach epidemic proportions globally (3). In recent decades obesity has reached worrying proportions in urban families with higher socioeconomic status and levels of education (4). In Brazil, there is a higher prevalence of obesity in the South and Southeast, including among children and youth $(27,52)$. 


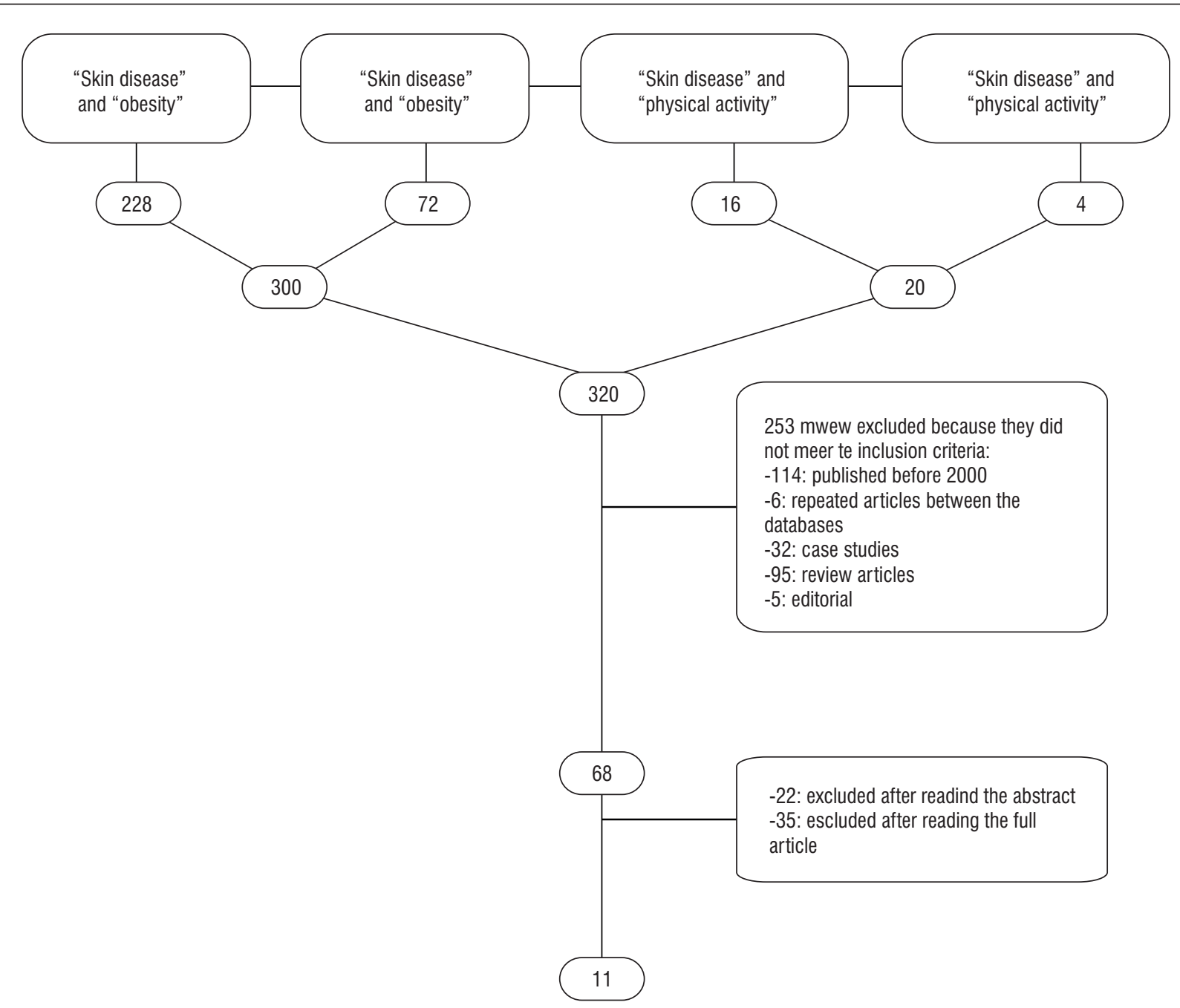

Figure 1 - Selection process of the studies included in this systematic The PEDro Scale was used to rate the methodological quality of the studies (Table 1)

Table 1 - Methodological quality of the studies analyzed in the systematic review

\begin{tabular}{|c|c|c|c|c|c|c|c|c|}
\hline Author & 1 & 2 & 3 & 4 & 5 & 6 & 7 & Total \\
\hline KALIL, G. & + & + & + & - & - & - & + & 4 \\
\hline SADEGHIAN, G. & + & + & - & - & - & + & + & 4 \\
\hline MUTAIRI, N. & - & - & - & - & - & - & + & 1 \\
\hline BOZA, J. & + & + & + & + & + & + & + & 7 \\
\hline GUIDA, B. & + & + & - & + & + & + & + & 6 \\
\hline AL-SAEED, W. & - & + & - & - & - & - & + & 2 \\
\hline ERDOGAN, B. & + & + & - & + & + & + & + & 6 \\
\hline NAEINI, F. & + & + & - & - & - & - & + & 3 \\
\hline NINO, M. & + & + & - & + & + & - & + & 5 \\
\hline SABAT, R. & + & + & - & + & + & + & + & 6 \\
\hline SHARQUIE, K. & + & - & - & - & - & - & + & 2 \\
\hline
\end{tabular}

Note: 1) Control group; 2) Group Similarity; 3) Sample calculation performed; 4) Use of reliable assessment instruments; 5) Appropriate statistical analysis; 6) QUALIS B1 or higher; and 7) Sample composed by more than 30 subjects. 


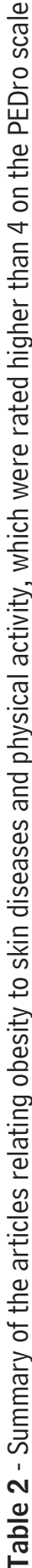

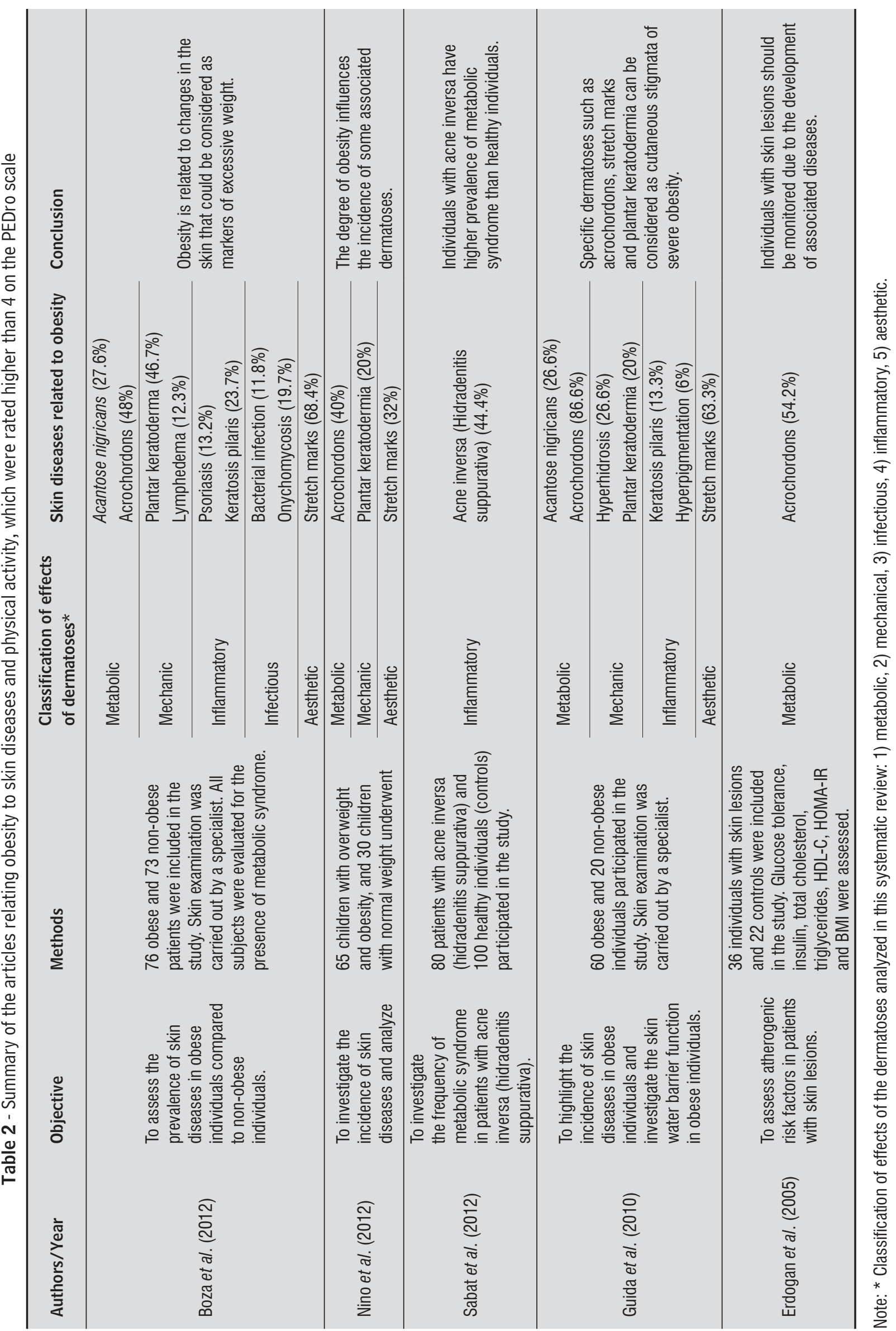




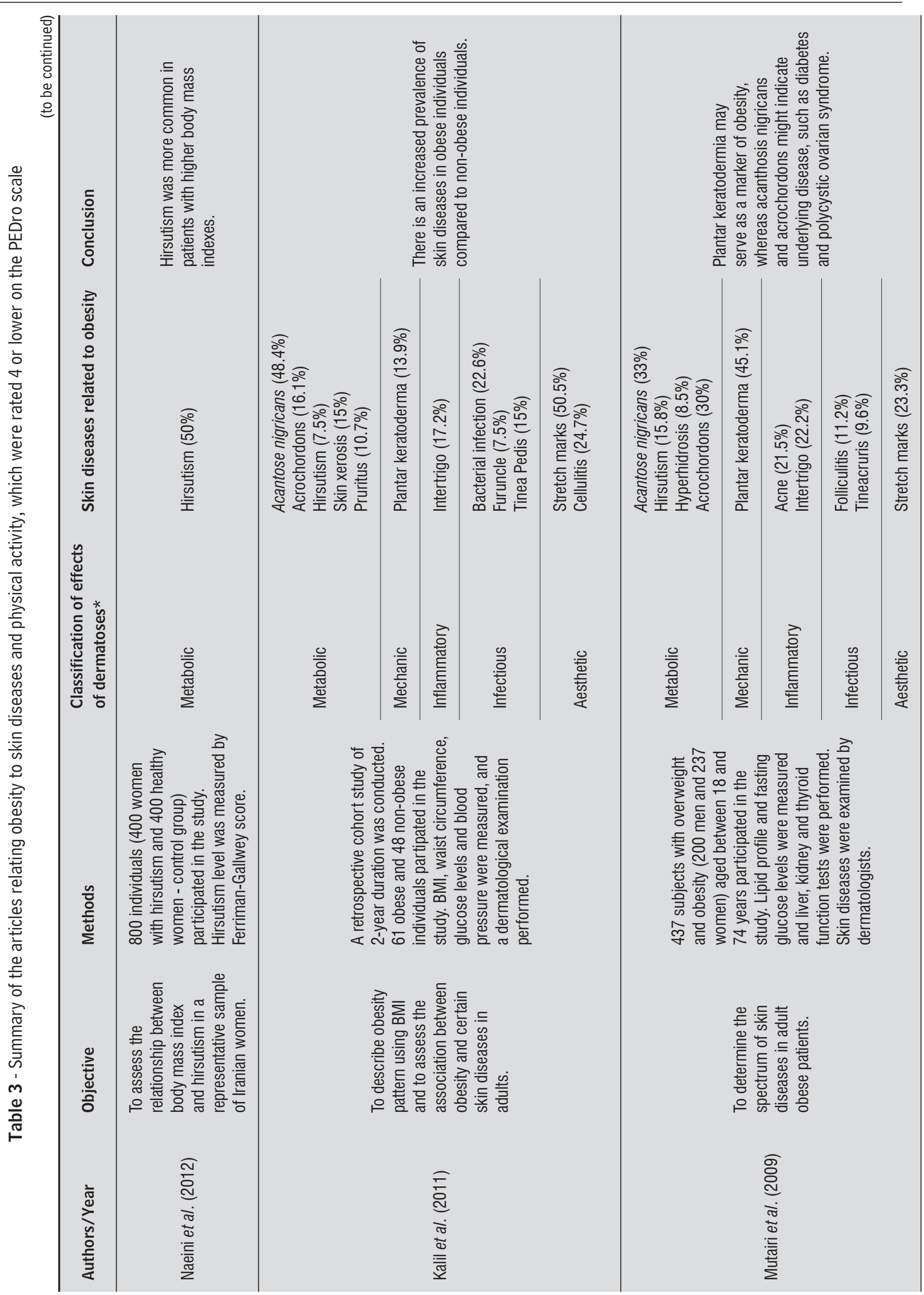




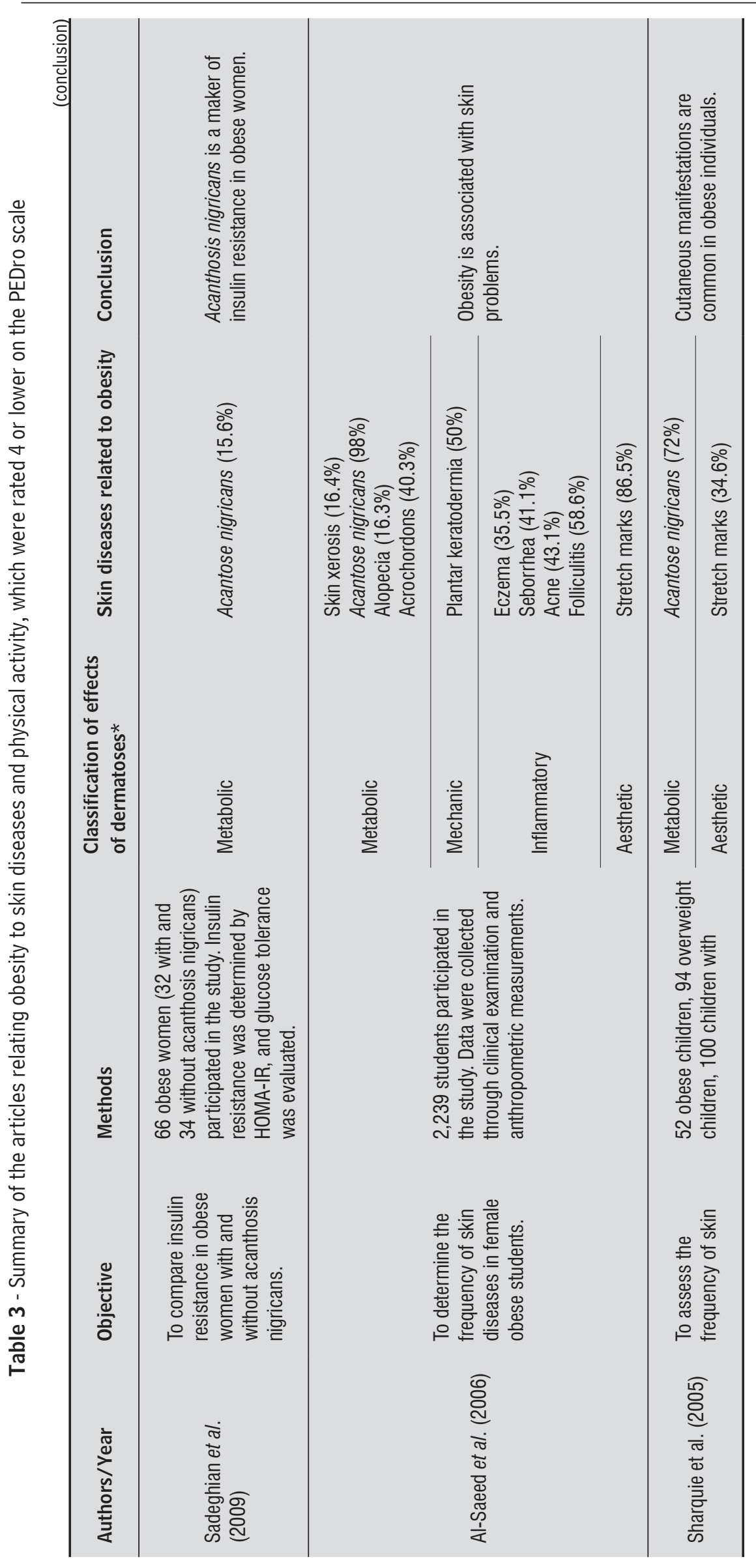


Progressive weight gain results from an imbalance between caloric intake and energy expenditure or is due to hypothyroidism, growth hormone deficiency, polycystic ovary syndrome, Cushing's syndrome, hypothalamic tumors, genetic syndromes, pregnancy, menopause or the use of medications such as steroids and psychotropics $(3,4)$. In sports and in the fashion industry, sudden weight fluctuations serve as warning signs for dysmorphophibia, cosmetic doping or bad diets followed in an attempt to quickly alter or shape the body $(26,53)$.

The main methods used to measure obesity are anthropometric measurements, such as body weight, subscapular/tricipital fold ratio, waist and hip circumference, and body mass index (BMI) $(3,4)$. A BMI between 18.5 and 24.9 is considered normal, between 25.0 and 29.9 is overweight, and 30.0 or above is obese. Morbid obesity is defined as being $100 \%$ over the ideal body weight or having a body mass index $(\mathrm{BMI})>40 \mathrm{Kg} / \mathrm{m}^{2}(2,18)$.

The waist-hip ratio (WHR) is a complementary index to the BMI in the assessment of obesity, which is diagnosed when WHR is $\geq 0.80 \mathrm{~cm}$ in women and $\geq 0.9 \mathrm{~cm}$ in men $(3,4,53)$.

Depending on the degree of obesity all organ systems are involved and show deviations from normality. Overweight and its consequences are associated with increased morbidity and mortality in adulthood $(54,55)$. Obese individuals are prone to cardiovascular, orthopedic, respiratory, endocrine, skin, psychiatric, gastrointestinal and liver disorders, as well as to carcinogenesis (gallbladder, uterus, breast) (4, 56). On the other hand, various restrictive diets adopted - often without proper planning - in the pursuit of weight loss lead to the development of nutritional deficiencies and psycho-affective disorders $(7,46)$.

For some obese individuals, the appearance of their skin only worsens pre-existing stigmas and their suffering, with negative consequences in the emotional state and in everyday life $(46,57)$. However, there is a lack of studies on the impact of dermatoses on participation in physical activity by obese individuals.

In this systematic review, we found that the incidence of certain dermatological manifestations (although they are not pathognomonic of obesity) was higher in the study group than in the control group $(1,2,29-31,33,37,43,47-49)$. The dermatoses were classified as metabolic in ten articles (91\%), as aesthetic in seven (64\%), as inflammatory in six (55\%), as mechanical in five (45\%), and as infectious in three
(27\%). All of them have significant implications for the practice of physical activity, as discussed below.

\section{Metabolic skin changes related to obesity}

The following metabolic manifestations have been detected in obese individuals: acanthosis nigricans, acrochordons, hirsutism and androgenetic alopecia $(1,2,29-31,33,37,43,48,49)$.

\section{Acanthosis nigricans}

Obesity-related acanthosis nigricans (pseudoacanthosis nigricans) is characterized by increased pigmentation of the skin in body folds of the armpits, the neck, the groin and intertriginous areas. It affects men and women almost equally and is more predominant in brown- and black-skinned individuals. Its development is insidious and associated with insulin resistance. The condition is asymptomatic and there is the formation of dark brown to black, lichenified or vegetating, rough plaques that give a "grimy" aspect to the skin. Weight gain and the scratching of the affected areas worsen the situation, as well as the dimension and evolution of the condition, making the skin surface rougher, thicker and more irregular. Rubbing, friction, sweating and ill-fitting sportswear trigger skin irritation, bleeding, discomfort and local pain during physical activities. Reduction in body weight improves acanthosis nigricans $(1,2,30,37$, $43,48,49)$.

\section{Acrochordons}

Acrochordons are small, benign, solid, elevated, pedunculated, non-contagious lesions, represented by asymptomatic, skin-color or dark brown, threadlike papules located in the cervical and axillary regions. This condition affects both healthy and obese individuals and is usually associated with acanthosis nigricans, endocrine diseases or personal characteristics of unknown etiology. Friction, rubbing and trauma due to sport, as well as scratching, can cause inflammation of the lesions and changes in color and size, and need to be examined by a physician in order to be differentiated from other dermatoses $(1,2,29$, $31,36,37,43,58$ ). 
Hirsutism and Androgenetic Alopecia

Hyperandrogenemia is associated with increased waist circumference $(>88 \mathrm{~cm})$ or increased waist/ hip ratio, insulin resistance, glucose intolerance and dyslipidemia. Laboratory tests show that a reduction in sex-hormone-binding-globulin levels (SHBG) and elevated total and/or free testosterone levels lead to hirsutism symptoms (32), acne and androgenic alopecia. Hirsute women usually show a reserved attitude, mood disorders such as anxiety and depression, and reduced willingness to perform simple everyday tasks or exercise $(1,33,37,59)$. The presence of acne, associated or not with polycystic ovary syndrome, may worsen patients' perception of the disease, their symptoms, functionality and emotions $(1,4,43)$.

Androgenetic alopecia in obese women or men may produce or be accompanied by varying degrees of emotional, social, family and professional impact (43). In addition, during physical activities outdoors, individuals with obesity and baldness are susceptible to sunburn and actinic keratoses on the exposed and unprotected areas of the scalp and need to use adequate photoprotection 60 .

\section{Diabetic dermopathy}

In predisposed individuals, obesity is a triggering factor for diabetes (56). Dermatoses act as specific markers of diabetes (necrobiosis lipoidica, disseminated annular granuloma, diabetic bullous disease, scleredema, acanthosis nigricans, eruptive xanthoma, diabetic dermopathy); as non-specific markers of diabetes (acrochordons, generalized itching, palmar/facial and nail erythema, pigmentary purpura); and as markers of complications, comorbidities, infections and drug reactions (35). The involvement of the superficial innervation by diabetic neuropathy in obese patients favors the development of injuries, chronic ulcers, perforating plantar disease and recurrent erysipelas (23). Physical activity, together with health education programs, healthy diets and the use medication, is required in order to control diabetes and obesity, and achieve a healthy lifestyle.

As noted earlier, metabolic cutaneous manifestations are grounds for complaints of discomfort and pain, and cause poor adherence of obese individuals to regular exercise programs. These manifestations negatively affect self-image and self-esteem, causing work difficulties, and feelings of insecurity, rejection and unhappiness $(7,46)$. On the other hand, studies show that physical activity focused on individual needs, abilities and purposes bring immediate and long-term benefits to weight control, depending on the organic adaptation to the effort (53). The exercise helps obese individuals control associated diseases and reduce irreversible and harmful consequences and complications.

\section{Mechanical skin changes related to obesity}

The main mechanical manifestation identified in obese individuals was plantar keratodermia (25). This condition is usually accompanied by ingrown nail, chronic venous insufficiency and lymphedema (20).

\section{Plantar keratodermia}

The thickening of the plantar stratum corneum (plantar hyperkeratosis or thick heel) is considered by some authors to be an obesity stigma, although it is not exclusive of this disorder. It is a multifactorial response to the excessive and repetitive overload to the plantar aspect of the heel may represent a risk of development of foot injuries. This condition is usually associated with calluses, fissures, infections and gait disorders, which limits physical activity $(1,2$, $25,30,37)$.

\section{Ingrown nail}

Ingrown or incarnated nails (onychocryptosis) are frequently found in the hallux of obese individuals due to factors such as foot shape, nail anatomy, use of tight shoes, hygiene habits, skin or systemic diseases. Ingrown nails hinder physical activity participation due edema, pain, local infection, musculoskeletal and joint overload, and postural changes. Weight loss leads to the improvement of foot edemas, nail trauma and plantar keratodermia, which, in turn, improves adhesion to walking and exercise programs. The recovery of gait autonomy facilitates obesity control (3-5). 
Chronic venous insufficiency and lymphedema

Obesity is a risk factor for chronic venous insufficiency in both men and women. Increased intraabdominal pressure increases resistance to venous return and leads to the development of stasis eczema, ocher dermatitis, lymphedema, leg ulcers and recurrent infections. This condition is associated with edema, pain and discomfort, resulting in a negative cycle of decreased mobility, increased inactivity and weight gain (2). In cases of infections and orthopedic or post-surgical situations, the drastic interruption of physical effort and the decreased energy expenditure at work and in daily life - associated with psychological factors - contribute to weight gain $(4,53)$.

A multiprofessional treatment together with the prescription of physical activity according to the profile of each case improves ergonomic fit, muscular capacity, endurance, balance, joint mobility, agility, walking speed and overall coordination. This is of vital importance for weight loss and general health, and is a determining factor for long-term maintenance of body mass $(51,53)$.

\section{Infectious skin changes related to obesity}

Studies with obese patients indicate an increased incidence of candidiasis, dermatophytosis, folliculitis, furuncles, erythrasma, hidradenitis suppurativa, erysipelas and cellulitis. During infectious processes patients may be instructed to temporarily avoid the practice of physical activities in order to prevent worsening of the condition and disease dissemination to the community $(5,8)$. However, weight reduction associated with extra local care aids in the control of infections and in the prevention of conditions. Longterm adherence to physical exercise shows positive impact on patient health.

Inflammatory skin changes related to obesity

$$
\text { Intertrigo }
$$

Intertrigo is frequently foun in obese individuals and results from chronic or acute inflammation of skin folds due to the combination of skin friction, heat and sweating. It is characterized by redness, scaling, erosion, crusting, oozing, itching and burning in the cervical, axillary, inguinal, inframammary and interdigital regions, and it is viewed as a main gateway to skin infections $(1,30,37)$. It is important to highlight that constant sweating of obese individuals favors the development of intertriginous lesions, and hinders the use of sports equipments and accessories, and causes physical, social and psychological disorders (30).

\section{Hidradenitis suppurativa}

Hidradenitis suppurativa (acne inversa) is a multifactorial chronic disease of the apocrine sweat glands. It is secreting and debilitating condition that is related to diabetes mellitus and obesity. The condition is associated with furuncles, recurrent abscesses and fistulas in the axillary and inguinal regions of young adults with oily skin. It progresses with pain, swelling, recurrent infection, dystrophic scars, suffering, social isolation and depression. Hidradenitis suppurativa causes emotional, aesthetic, sexual, and economic disorders. Severe forms are accompanied by acne conglobata, pilonidal cyst and dissecting folliculitis of the scalp, forming the "tetrad of follicular occlusion". There are rare reports of malignant transformation into squamous cell carcinoma and systemic complications such as anemia, hypoproteinemia, arthropathy and amyloidosis $(2,47)$.

\section{Seborrheic Dermatitis}

Seborrheic dermatitis is a common non-contagious chronic inflammatory skin condition that affects predisposed individuals, obese or not. It is characterized by oily, erythematous, scaly plaques on the scalp, face, neck, back, breast, armpits and groin. Dandruff is its most common symptom. The scaly appearance of the skin can cause discomfort, prejudice and social difficulty, hindering the practice of physical activities in public $(2,43)$.

\section{Psoriasis}

Studies have shown that obesity contributes to the development or exacerbation of psoriasis. The presence of dry and excessive scales on the skin affects the quality of life of people with psoriasis and the presence of arthritis may be limiting (34). Appropriate 
approaches help prevent arthralgia, reduce postural difficulties, raise self-esteem and tolerance to pain by reducing barriers to physical activity.

Inflammatory skin changes have profound effects on the functionality of patients due to pain, suffering, embarrassment, prejudice and discrimination, which decrease motivation and adherence to physical activities (2, 39-42). In these cases, personalized exercise programs may help overcome limitations, minimizing losses in daily life, personal and professional relationships, recreation, mental health and vitality, and favoring medical treatment.

\section{Aesthetic skin changes related to obesity}

Stretch marks and cellulitis

Stretch marks are linear, elevated pink to violaceous lesions that occur most commonly after excessive dermal stretching. They develop into white atrophic wrinkled lines and their pathogenesis is not completely understood. Stretch marks are observed associated with obesity, pregnancy, pubertal growth spurts, Cushing's syndrome, use of corticosteroids, aesthetic placement of breast implants and rapid muscle increase (26). In obese individuals, they are most commonly observed on the abdomen, breast, upper arms, lower back, buttocks, thighs, and groin. Control and reduction of excess weight may prevent their evolution. Several drugs, cosmetics and technological resources have been proposed for their treatment. However, so far no intervention has proven curative and absolutely exempt from risks or adverse effects $(1,2,26,30,43,49)$.

Gynoid lipodystrophy (cellulitis) has an unknown etiology and is common in women after puberty. Cellulitis is influenced by sedentary lifestyle, obesity, heredity, age, sex, pregnancy, use of hormonal contraceptives, hormonal disorders, smoking, inadequate nutrition, circulatory changes and mechanical factors. It changes the appearance, the shape and the size of the thighs, the abdomen and the gluteal region, giving a corrugated nodular (orange peel-like) appearance to the skin. Despite causing discomfort and pain, this condition tends to be underdiagnosed because patients are often too embarrassed to seek medical attention.

The symbolic representation of the obese body with skin diseases is probably associated with feelings of inferiority, inadequacy and depreciation due to negative external judgments $(26,46)$. The dissatisfaction with the body and sometimes rejection of the body, the occurrence of social, professional or family disturbances, and the presence of existing comorbidities and skin diseases affects the lifestyle of obese individuals and may jeopardize their ability to perform daily tasks and their motivation to practice physical activities. Social inhibition occurs due to shame, frustration, hopelessness, stigmatization, segregation, depression and anxiety (18).

However, proper exercise prescription helps improve body image, encourages socialization and long-term adherence to exercise and may help gradually increase positive attitudes toward weight control and health care (36).

\section{Future prospects}

The increasing changes in eating habits and energy expenditure patterns, resulting from industrial and technological advances are likely to increase the tendency toward obesity or overweight in genetically susceptible individuals exposed to unfavorable environmental factors $(3,4,15)$.

The fight against physical inactivity needs to encourage daily physical activity and cardiovascular low-impact exercise in a playful and pleasurable way. Studies show that dietary re-education combined with increased physical activity and multidisciplinary support is the most effective approach in the medium to long term $(4,28,51,52)$.

Paying attention to skin diseases related to obesity is of paramount importance in order to transmit positive signals to the individual regarding his/her condition as a person, restore his/her health and improve his/her self-image, self-esteem and emotional stability. Regular physical activity is essential in this process. It is recommended for fitness, therapy, recreation and socialization, and minimizes or eliminates damage, injuries, emotional and financial costs to current or former obese individuals, their families and the community.

This review showed that there is a high frequency of metabolic, mechanical, inflammatory, infectious and aesthetics disorders in obese individuals and that such disorders should be considered when analyzing adherence to physical activities. 
The most commonly found conditions were: acanthosis nigricans, acrochordons, stretch marks, plantar keratodermia, intertrigo and skin infections.

Considering that the approach to individuals with obesity includes the implementation of strategies for the promotion, protection and recovery of health, the reduction of dermatologically-related limitations together with the personalized prescription of regular physical activity play an important role in promoting global health care.

\section{References}

1. Mutairi, N. Associated cutaneous diseases in obese adult patients: a prospective study from a skin referral care center. Med Princ Pract. 2011;20:248-52.

2. Boza JC, Trindade EN, Peruzzo J, Sachett L, Rech L, Cestari TF. Skin manifestations of obesity: a comparative study. JEADV. 2012, 26:1220-3.

3. BRASIL. Ministério da Saúde. Secretaria de Atenção à Saúde. Departamento de Atenção Básica. Obesidade/ Ministério da Saúde, Secretaria de Atenção à Saúde. Departamento de Atenção Básica. Brasilia: Ministério da Saúde, 2006. 128p. Cadernos de Atenção Básica, n. 12 . Série A. Normas e Manuais Técnicos.

4. ABESO [internet]. Diretrizes Brasileiras de Obesidade. $3^{\text {th }}$ edition. 2009. [Cited on 2014 jun 30]. Available from: http://tinyurl.com/ao8b9ev

5. Segula D. Complications of obesity in adults: a short review of the literature. Malawi Med J. 2014;26(1):20-4.

6. Shipman AR, Millington GWM. Obesity and the skin. Br J Dermatol. 2011;165(4): 743-50.

7. Yosipovitch G, DeVore A, Dawn A. Obesity and the skin: skin physiology and skin manifestations of obesity. J Am Acad Dermatol. 2007;56:901-16.

8. Garcia Hidalgo L. Dermatological complications of obesity. Am J Clin Dermatol. 2002;3:497-506.

9. Hahler B. An overview of dermatological conditions commonly associated with the obese patient. Ostomy Wound Manage. 2006;52(6):34-6.

10. Martalo O, Pierard Franchimont C, Scheen A, Pierard GE. Skin diseases and obesity. Rev Med Liege. 2003; 58:73-6.
11. Mathur AN, Goebel L. Skin findings associated with obesity. Adolesc Med State Art Rev. 2011;22(1):146-56.

12. Rivers JJ. Addressing obesity related skin-disease. Cutan Med Surg. 2012;16(6):381-4.

13. Scheinfeld NS, Parish DH, Parish LC. A primer of skin diseases associated with obesity. Expert Rev Dermatol. 2007;2:409-15.

14. Scheinfeld NS. Obesity and dermatology. Clin Dermatol. 2004;22(4):303-9.

15. Strumia R. Dermatologic signs in patients with eating disorders. Am J Clin Dermatol. 2005;6:165-73.

16. Tobin AM, Ahern T, Rogers S, Collins P, O'Shea D, Kirby B. The dermatological consequences of obesity. Int J Dermatol. 2013;52(8):927-32.

17. Garcia-Hidalgo L, Orozco-Topete R, Gonzalez-Barranco J, Villa AR, Dalman JJ, Ortiz-Pedroza G. Dermatoses in 156 obese adults. Obes Res. 1999;7:299-302.

18. Almeida GAN, Loureiro SR, Santos JE. A imagem corporal de mulheres morbidamente obesas avaliada através do desenho da figura humana. Psicologia: reflexão e crítica. 2002;15(2):283-92.

19. Araujo LMB, Viveiros AMC, Lopes RC, Viana AC, Fukui RT, Ursich MJM. Acanthosis nigricans em mulheres obesas de uma população miscigenada: um marcador de distúrbios metabólicos. An. Bras.Dermatol. [online]. 2002,77(5):537-43.

20. Araujo LM, Porto MV, Netto EM, Ursich MJ. Association of acanthosis nigricans with race and metabolic disturbances in obese women. Braz J Med Biol Res. 2002;35:59-64.

21. Jabbour SA. Cutaneous manifestations of endocrine disorders: a guide for dermatologists. Am J Clin Dermatol 2003;4:315-31.

22. Kaur J. A comprehensive review of metabolic syndrome. Cardiology Research and Practice. 2014:1-21.

23. Demirseren DD, Emre S, Akoglu G, Dilek Arpaci D, Aysegul Arman A, Metin A, BekirCakir B. Relationship between skin diseases and extracutaneous complications of diabetes mellitus: clinical analysis of 750 patients. Am J Clin Dermatol. 2014;15:65-70. 
24. Kluczynik CEN, Mariz LS, Souza LCF, Solano GB, Albuquerque FCL, Medeiros CCM. Acanthosis nigricans and insulin resistance in overweight children and adolescents. An Bras Dermatol. [online]. 2012, 87(4):531-7.

25. Filippin NT, Barbosa VLP, Sacco ICN, Lobo da Costa, PH. Efeitos da obesidade na distribuição de pressão plantar em crianças. Rev Bras Fisioter. 2007; 11(6):495-501.

26. Mota, CG; Aguiar, EF. Dismorfia muscular: uma nova síndrome em praticantes de musculação. Revista Brasileira de Ciências da Saúde 2011;9(27):49-56.

27. Poeta LS, Duarte MFS, Giuliano ICB. Qualidade de vida relacionada à saúde de crianças obesas. Rev Assoc Med Bras. 2010;56(2):168-72.

28. Tahara AK, Schwartz G M, Silva KA. Aderência e manutenção da prática de exercícios em academias. R. Bras Cienc Mov. 2003;11(4):7-12.

29. Nino M, Franzese A, Perrino N R, Balato N. The effect of obesity on skin disease and epidermal permeability barrier status in children. Pediatric Dermatology. 2012,29(5);567-70.

30. Guida B, Nino M, Perrino NR et al. The impact of obesity on skin disease and epidermal permeability barrier status. J Eur Acad Dermatol Venereol. 2010;24:191-5.

31. Erdogan BS, Aktan S, Rota S, Ergin S, Evliyaoglu D. Skin tags and atherosclerotic risk factors. J Dermatol. 2005;32:371-5.

32. Naeini FF, Najafian J, Jazebi N. Hirsutism and body mass index in a representative sample of Iranian people. ARYA Atherosclerosis J. 2012;8(1):43-5 .

33. Abdul-Aziz A, Nayaf MS, Mauloodd KJ. The relationship of body mass index and hirsutism in adult females. Our Dermatol Online. 2015; 6(3):276-9.

34. Padhi T, Garima A. Metabolic syndrome and skin: psoriasis and beyond. Indian J Dermatol. 2013; 58(3): 299-305.

35. Murphy-Chutorian B, Han G, Cohen SR. Dermatologic manifestations of diabetes mellitus: a review. Endocrinol Metab Clin N Am. 2013;42:869-98.

36. Wenczl E. Skin manifestations, treatment and rehabilitation in overweight and obesity. Orv Hetil. 2009; 150(37):1731-8.
37. Khalil GM, Al Shobailic HA, Alzolibanic A, Robaeec AA. Relationship between obesity and other risk factors and skin disease among adult Saudi population. J Egypt Public Health Assoc. 2011,86:56-62.

38. Huttunen R, Syrjänen J. Obesity and the risk and outcome of infection. Int J Obes. 2013;37(3):333-40.

39. Armstrong AW, Harskamp CT, Armstrong EJ. The association between psoriasis and obesity: a systematic review and meta-analysis of observational studies. Nutr Diabetes. 2012;2(12):1-10.

40. Duarte GV, Follador I, Cavalheiro CMA, Silva TS, Oliveira MFSP. Psoriase e obesidade: revisão de literatura e recomendações no manejo. An Bras Dermatol. 2010; 85(3):355-60.

41. Johnston A, Arnadottir S, Gudjonsson JE, Aphale A, Sigmarsdottir AA, Gunnarsson SI, et al. Obesity in psoriasis: leptin and resistin as mediators of cutaneous inflammation. Br J Dermatol. 2008;159:342-50.

42. Kim N, Thrash B, Menter A. Comorbidities in psoriasis patients. Semin Cutan Med Surg. 2010;29:10-5.

43. Al-Saeed WY, Kasim MA, Bahnassy A. Dermatoses in obese female school children in the al-khobar area, eastern saudi Arabia. J Family Community Med. 2006; 13(2): 65-9.

44. Rehme MFB, Pontes AG, Goldberg TBL, Corrente JE, Pontes AG. Manifestações clínicas, bioquímicas, ultrassonográficas e metabólicas da síndrome dos ovários policísticos em adolescentes. Rev Bras Ginecol Obstet. [online]. 2013;35(6):249-54.

45. Foss NT, Polon DP, Takada MH, Foss-Freitas MC, Foss MC. Dermatoses em pacientes com diabetes mellitus. Rev Saude Pub. 2005;39(4);677-82.

46. Magnusson M, Sørensen TI, Olafsdottir S, LehtinenJacks S, Holmen TL, Heitmann BL, et al. Social inequalities in obesity persist in the nordic region despite its relative affluence and equity. Curr Obes Rep. 2014;7(3):1-15

47. Sabat R, Chanwangpong A, Schneider-Burrus S, Metternich D, Kokolakis G, Kurek A, et al. Increased prevalence of metabolic syndrome in patients with acne inversa. PLoS One. 2012;7(2):1-9.

48. Sadeghian G, Ziaie H, Amini M, et al. Evaluation of insulin resistance in obese women with and without acanthosis nigricans. J Dermatol. 2009;36:209-12. 
49. Sharquie KE, Al Rawi JR, Al Tamimi FF. The frequency of skin diseases in obese children and adult Iraqi population. Saudi Med J. 2005;26:1835-6.

50. Shiwa SR, Costa LOP, Moser ADL, Aguiar IC, de Oliveira LVF. PEDro: a base de dados de evidências em fisioterapia. Fisioter Mov. 2011 jul/sep;24(3):523-33

51. Matsudo SM, Matsudo VR, Andrade DR, Araujo TL, Andrade E, Oliveira L, et al. Physical activity promotion: experiences and evaluation of the Agita Sao Paolo Program using the ecological mobile model. J Phys Activity Health. 2004;1(1):81-97.

52. Leite N, Milano GE, Cieslak F, Lopes WA, Rodacki A, Radominski RB. Effects of physical exercise and nutritional guidance on metabolic syndrome in obese adolescents. Rev Bras Fisioter. [online]. 2009,13(1):73-81.

53. Gorayeb. N, Costa RVC, Daher DJ, Oliveira Filho JÁ, Oliveira MAB, et al. Diretriz em cardiologia do esporte e do exercício da sociedade brasileira de medicina do esporte. Arq Bras Cardiol 2013:100(1Supl.2):1-41.

54. Giugliano R, Carneiro E. Fatores Associados à obesidade em escolares. J Pediatr. 2004,80(1):17-22.

55. Kalichman L, Livshits GG, Kobyliansky E. Indices of body composition and chronic morbidity: a crosssectional study of a rural population in central Russia. American Journal of Human Biology. 2006;18:350-8.
56. Millington GW. Obesity, genetics and the skin. Clin Exp Dermatol. 2013;38(1):50-6.

57. Lowe JR. Skin integrity in critically ill obese patients. Crit Care Nurs Clin North Am. 2009;21(3):311-22.

58. Tamega AA, Aranha AMP, Guiotoku MM, Miot LDB, Miot HA. Associação entre acrocórdons e resistência à insulina. An Bras Dermatol. 2010;85(1):25-33.

59. Flores CB, Flores L, Comim FV. Hirsutismo: avaliação e princípios do tratamento. Revista da AMRIGS. 2013; 57(3):232-9.

60. Purim KSM, Leite N. Fotoproteção e exercício físico. Rev Bras Med Esporte. 2010; 16(3):224-9.

Received: 10/22/2014

Recebido: 22/10/2014

Approved: 05/12/2015

Aprovado: 12/05/2015 